\title{
FORMACIÓN DOCENTE Y ESCUELA: POSIBLES ARTICULACIONES
}

School Teacher Training and Potential Joints

\section{Celeste Abréu Van Grieken*}

Resumen: Este artículo pretende suscitar una reflexión sobre la articulación entre formación docente, escuela y contexto. Analiza la formación docente en perspectiva de la construcción de nuevas subjetividades y del rol de los docentes desde una epistemología hermenéutica y de políticas sistémicas. Finaliza valorando los aportes de las Ciencias Sociales a la formación docente en el marco del paradigma interpretativo y del pensamiento complejo inter y transdisciplinar y, desde esa visión, aporta las sugerencias correspondientes.

Palabras clave: Formación docente, subjetividades, paradigma interpretativo, contexto, interdisciplinar, transdisciplinar, identidades, ciudadanía.

Directora Equipo Técnico, Oficina de Certificación y Desarrollo de la Carrera Docente, Ministerio de Educación. Correo electrónico: abreuceleste@hotmail.com 


\begin{abstract}
This article aims to stimulate reflection on the relationship between teacher education and school context. Analyzes the perspective of the teacher training in the construction of new subjectivities and the evaluation of the role of teachers from systemic policies and epistemology hermeneutics. End valuig the contributions of social sciences teacher training under the interpretative paradigm and the complex an inter-disciplinary thinking and from that vision, provides the relevant suggestions.
\end{abstract}

Keywords: Teacher training, subjectivities, interpretive paradigm, context, interdisciplinary, transdisciplinary, identities, citizenship.

\title{
1. Introducción
}

Existe una plena conciencia de que la formación inicial docente constituye uno de los factores más relevantes de la calidad de la educación. Se espera que su impacto en el ejercicio profesional docente se evidencie en la dinámica de la escuela de hoy, que opera en un contexto definido por grandes cambios y transformaciones en todos los ámbitos de la sociedad, la ciencia y la cultura.

Es precisamente a partir del marco de interacciones y responsabilidades entre escuela- contexto donde los docentes tienen la importante función de promover procesos de aprendizaje que hagan visibles las bondades y perversiones de la realidad. 
Ese desafío no es posible sin que la formación inicial esté vinculada a los rasgos que definen el contexto actual, pues no es suficiente con enseñar sin cuestionar la realidad, sino para propiciar conocimientos, valores y actitudes que posibiliten reconocerse a sí mismo como individuo y como colectividad, es decir, como sujetos capaces de asumir acciones transformadoras en la sociedad, en lugar de seres adaptativos e incapaces de actuar como agentes del cambio social.

\section{Escuela, contexto y formación docente}

A pesar de que entre escuela y comunidad existe una relación dialéctica, altos muros intentan separarlas de sus comunidades y de las situaciones - problemas que pueden dar sentido a la vida del aula; pero a pesar de los obstáculos físicos y simbólicos que se interponen en esa relación, también

En la escuela entran la pobreza y la exclusión social, las culturas juveniles y adolescentes, la violencia, la enfermedad, el miedo, la inseguridad, la droga, el sexo, el compañerismo, el altruismo, la amistad. (Tallone, 2010: 160)

Por tanto es evidente que lo cotidiano y lo emergente del contexto y todo lo que ocurre fuera de la escuela forma parte de ella e incide en su funcionamiento. Considerando la importancia de esa relación y, siguiendo los planteamientos de Tedesco (2005), citado por López (2007: 71):

La escuela necesita asumir una posición más crítica ante los valores que existen fuera de ella, que permean sus aulas, para discutirlos y cuestionarla. La escuela tiene la capacidad de resistir prácticas sociales excluyentes, fragmentarias, individualistas o antisociales que se instalan cada vez más en nuestro medio. Asumir la capacidad política de la escuela es, precisamente, no tolerar de brazos cruzados los efectos 
de las crecientes desigualdades y de la crisis de cohesión social dentro de la institución educativa ni en la comunidad.

$\mathrm{Y}$ es que a la escuela se asiste no solo para aprender a leer y escribir. La escuela que necesitamos hoy es más que eso: Es un espacio privilegiado, para que estudiantes profesores, familia y comunidad aprendan a ser mejores ciudadanos, ser solidarios, construir y fortalecer identidades, en fin, para desarrollar valores que permitan la convivencia en una sociedad democrática, justa y equitativa. De ahí que necesita reinventarse pues

Las instituciones escolares desempeñan un papel destacado en el proceso de convertir en visible la realidad; facilitan el que determinados acontecimientos, objetos y personas cobren existencia y se incorporen a la memoria de la humanidad; coadyuvan, junto con otras instituciones y con los medios de comunicación de masas, a la creación y definición de realidades, de acontecimientos y personajes con sus correspondientes valores y significados. (Torres, 2011: 107)

Se impone, pues, potenciar una nueva lectura de esa realidad, reconociéndola como multidimensional lo cual nos aboca a superar el encierro de la escuela y a ver el mundo desde diferentes perspectivas: política, económica y socio-cultural. Se espera que una formación docente de calidad tenga su impacto en el desempeño docente y, por supuesto, en los aprendizajes escolares. En esos aprendizajes los docentes constituyen un factor de primer orden, pues con sus propuestas de trabajo en aula pueden incidir en sus estudiantes con una actitud adaptativa a la realidad o en el establecimiento de relaciones de enfrentamiento con esa realidad con tal de transformarla. En ese sentido, cabe recordar que no existen prácticas educativas neutras.

Si la formación docente debe preparar para desempeñar la compleja variedad de roles que se atribuye a la escuela, cómo puede integrarse a esa formación y, por ende, a los procesos de aprendizaje 
las fragmentaciones de todo ese tejido que llamamos sociedad y de la cual somos parte. ${ }^{1}$

¿Para qué escuela se están formando los docentes del país? ¿Cuál es la visión de la escuela que se construye desde los programas de formación docente? ¿La de una escuela acabada o en permanente construcción? ¿Una escuela y una formación docente que separan o integran saberes, estudiantes, familia, comunidad? ¿Una escuela cuya propuesta pedagógica esté orientada al cambio o adaptada al status quo? ¿Qué nuevos roles se requieren del docente para funcionar efectivamente bajo las condiciones señaladas? En definitiva, ¿cuál es la formación docente que necesitamos hoy en contextos marcados por el cambio, la incertidumbre, la desigualdad, la exclusión, la violencia, entre otros factores?

\section{Los maestros y las maestras como sujetos que aprenden}

Si la educación pretende la realización plena de los seres humanos para convivir juntos en la sociedad, ha de pensarse la formación docente recuperando, el concepto de sujetos al que, por derecho, todo individuo está llamado a ser. Reconocer al docente como sujeto tiene muchas implicaciones: Asumir la propia historia con una clara conciencia de la realidad; mantener una actitud no adaptativa, sino crítica frente a los problemas del ser humano y de la sociedad; asumir un compromiso con la transformación de su propio contexto. Se trata de un ser humano en permanente construcción y en constante diálogo con el contexto. Un sujeto situado cuya representación de la realidad nunca es estática, sino evolutiva. Por tanto, moviliza, con pasión, sus capacidades de reflexionar sobre ella, la interpela y la transforma.

1 Justamente reflexionando sobre la escuela dominicana, Scheker (2003: 43) destaca que la magnitud de los cambios que hay que realizar en la educación obliga al compromiso de todos y añade que la escuela no puede verse como objeto de transformación, sino como sujeto del cambio. 
Como plantea Assman, se trata (2002: 106) de una visión epistemológica en la cual "los sujetos aprendientes se mantienen en estado hermenéutico, es decir, en situación de estar y seguir descubriendo la realidad". En otras palabras, un sujeto con capacidad de asombro, apasionado del saber y en permanente actitud para el aprendizaje durante toda la vida. Un sujeto en contacto permanente con las diferentes manifestaciones de la cultura porque es muy obvio como expresan Aguerrondo y Braslasvky (2003: 29) que Nadie que no comprenda el mundo puede realmente orientar a los niños y jóvenes a promover aprendizajes para el siglo XXI. Esto implica que un desafío fundamental de la formación docente es ampliar el horizonte cultural".

$\mathrm{Al}$ repensar la formación docente surgen muchas preguntas que pueden enriquecer la reflexión: ¿Qué nuevas posibilidades de intervención tendrían nuestros docentes desde una formación que contribuya a su construcción como sujetos para que, a su vez, puedan apoyar la construcción de otros sujetos? ¿Cómo puede transitarse hacia una formación docente que promueva la construcción de realidades abiertas y de saberes no acabados?

¿Es posible una formación docente eminentemente reflexiva que promueva el desarrollo de habilidades y competencias profesionales, así como el desarrollo del ser, es decir, de la persona? ¿Cómo vivir desde la formación inicial la experiencia de ser sujeto, capaz de reconocerse en el otro y construirse junto a él o ella? ¿Cómo apoyar la construcción de esa subjetividad, asumida como la búsqueda del sentido de su vida y de su formación profesional? ¿Es posible comprender desde esa formación el valor de la responsabilidad por los propios actos en todas las dimensiones de su vida personal, profesional y social? ¿En qué medida ese valor permitirá superar la resistencia a la crítica profesional y no asumirla como un elemento amenazante? ¿Qué tipo de articulación curricular realizan las instituciones formadoras de docentes con las instituciones científicas, culturales, ambientales y de derechos humanos que permitan a 
los futuros docentes vivir el ser sujeto como parte de los procesos naturales de su formación, su compromiso social y su futuro ejercicio docente?

$\mathrm{Al}$ adentrarse en la reflexión sobre la formación docente surge el cuestionamiento de si la formación de los futuros docentes los confronta a reconocerse a sí mismos y colectivamente como sujetos, es decir, como agentes del cambio educativo, pues como expresa Fullan:

En todas las fases de sus respectivas carreras, los educadores tienen la responsabilidad de actuar: Los profesores principiantes, aportando nuevas ideas y energías a la profesión y evitando sucumbir a los aires viciados de la rutina; los que se encuentran en el medio de su carrera, saliendo del estancamiento, y los docentes experimentados, transmitiendo su sabiduría, en vez de su escepticismo. (1997: 142)

\section{Enfoques para repensar la formación docente}

A pesar de los esfuerzos realizados en el país para titular docentes e impulsar procesos de formación continua, aún permanecen los desencuentros entre esa formación y las necesidades formativas docentes. Tal como expresa Vaillant (2004: 23): "Ya no alcanza con que un maestro o profesor sepa lo que va a enseñar y tenga una buena formación acerca del proceso de enseñanza y aprendizaje. La complejidad de la tarea exige un cambio de enfoque".

En otras palabras, implica un cambio en las concepciones de los programas de formación docente que requieren enfatizar no solo el qué, el para qué, y el para quién, sino el cómo, ya que a juicio de Marcelo y Vaillant (2009: 84), ha sido el tipo de conocimiento más descuidado, pues se trata de un "conocimiento tácito, es decir, que no se ha documentado ni se ha hecho explícito por la persona que lo posee". 
Hacer explícito ese conocimiento no es posible sin generar desde la formación tiempo y espacio para la reflexión de tal manera que la misma se integre como un hábito inseparable de la actuación docente. Dedicar espacio y tiempo para la reflexión en una sociedad urgida por la prisa y el inmediatismo no significa tiempo perdido. Más bien,

Necesitamos una pausa para que ocurra la toma de conciencia y la reorganización del hacer. Pero una pausa no es parálisis, sino un silencio en el compás de una melodía cuya función es realzar e intensificar la percepción de la nota siguiente o imprimir un ritmo diferente, un quiebre en la rutina, el acostumbramiento y la expectativa de quienes están oyendo. A esta calidad de pausa, nos referimos cuando pensamos en recuperar el espacio y el tiempo para la reflexión. Estas pausas no se generan espontáneamente y necesitan ámbitos colectivos para producirlas y utilizarlas. (Anijovich, 2009: 58)

Esos espacios de reflexión, si son bien aprovechados, crean las condiciones para generar y valorar la producción del conocimiento pedagógico, cuestionar la práctica para aprender de ella, descubrir su sentido y renovarla. En fin, tan importante es lo que se aprende como el modo en que se integra ese aprendizaje a los saberes y experiencias previos de los sujetos.

¿Será posible que en el conjunto de cambios que se vislumbran en la formación docente se prioricen modelos y enfoques cuyos ejes sean la reflexión, la investigación y la producción de conocimiento? ¿Cómo promover en el proceso de formación inicial la recuperación del hábito del silencio, condición fundamental para pensar y reflexionar individualmente? ¿Superaremos la susceptibilidad idiosincrática ante la crítica para que los centros educativos también sean espacios de aprendizaje profesional docente? ¿En qué medida el currículo de formación inicial incide en la persona de los futuros docentes, en su compromiso social y en la recuperación de las utopías, ese necesario espacio donde se cultiva la 
esperanza para hacer realidad otro mundo porque "si bien ahora tenemos claro que no hay certezas sobre el futuro ni puede haberla, sin embargo las imágenes del futuro influyen en el modo en que los seres humanos actúan en el presente" (Wallestern, 2006: 85).

Por otra parte, ¿̇en qué medida la formación docente que reciben nuestros maestros(as) trabaja con sus sueños, reconociendo que son el motor que puede impulsar los cambios que necesitan llevar a cabo para fortalecer su práctica? ¿Desde qué nuevas subjetividades se articulan esos sueños con las vivencias formativas que los aproximen a una relación respetuosa con su contexto, con las otras personas y con el mundo?

\section{Formación docente y Ciencias Sociales}

Pensar la formación docente desde las Ciencias Sociales, implica el reconocimiento de cómo estas ciencias, a partir del siglo XX, han logrado trillar su propio camino y han dado origen al paradigma de la interpretación. En palabras de Wallestern et al. (2006):

En efecto, nuevas concepciones empezaron a dar lugar a todo aquello que la visión empírico- analítica había excluido: La historia y las ideologías implícitas en el conocimiento; los valores y los significados sociales en la constitución de las prácticas y, sobre todo, junto a eso, los sujetos capaces de producir saberes acerca de lo social, desde los anclajes culturales de sus propios mundos de vida.

Esta perspectiva, aporta una nueva dimensión a la formación docente dado su interés por la comprensión y el significado de las acciones humanas y de la práctica social como fuente generadora de conocimientos. Al conceder especial atención al valor de lo narrativo, permite la recuperación e interpretación de esas historias contadas durante el proceso formativo y el desarrollo de las habilidades y competencias para captar lo singular y lo propio de cada situación de aprendizaje, ya sea desde la propia biografía o de los 
estudiantes. Permiten, por tanto, develar aspectos que pueden ser invisibles de no someterse a un proceso reflexivo que permita reconstruir la experiencia.

Otra perspectiva desafiante para la formación docente procede de los aportes de Edgar Morín (1999: 92) quien plantea la necesidad de un pensamiento complejo que integre los conocimientos de las distintas disciplinas como parte de un todo, que "reconozca y analice los fenómenos multidimensionales... que reconozca y analice realidades que son al mismo tiempo solidarias y conflictivas... que respete lo diverso y al mismo tiempo reconozca la unidad."

Esa visión integradora se contrapone a la concepción tradicional que durante varios siglos se ha internalizado y asumido como un paradigma permanente: la visión del conocimiento en estancos o parcelas disciplinares.

Sin denostar el valor de las disciplinas como organizadoras del conocimiento, el análisis del modelo disciplinar que se ha mantenido vigente en los sistemas educativos condiciona una manera de enseñar y aprender de los sujetos que desconocen los desencuentros entre teorías opuestas. En consecuencia, se pierde la oportunidad de enriquecer el conocimiento con distintas visiones sobre un fenómeno que, en algunos casos, podrían ser complementarias y, en otros, simplemente aportan otra mirada diferente, pero necesaria de esa realidad.

De ahí que la propuesta de Morin de abordar el conocimiento desde una perspectiva multi, inter y trandisciplinaria debería ser considerada para la formación docente como una forma de superar las fragmentaciones del conocimiento.

La propuesta de Morin es coherente con el cómo de los procesos de aprendizaje de las personas, por su carácter global y no aislado (por disciplinas) atribuido a ese aprendizaje. Basta recordar los aportes de Decroly, la psicología piagetiana y la teoría de la percepción de la Gestalt a favor de metodologías globalizadoras de aprendizaje-enseñanza. 
La complejidad del mundo actual plantea serios desafíos a la formación docente, pues no basta con tener una titulación. Se necesitan profesionales cuya formación polivalente les permita accionar ante una diversidad de situaciones no previsibles ya que el cambio no se detiene. Asumir esa realidad y formar docentes con actitudes de flexibilidad, apertura y criticidad ante lo viejo, lo nuevo y lo emergente debería estar en el foco del currículo y de las experiencias que caracterizan la cultura de las instituciones formadoras.

\section{Desafíos de la formación docente}

Desde las reflexiones anteriores, nos parece que la formación docente que necesitamos ha de responder a las siguientes necesidades:

- Una formación que parta de los intereses de los sujetos y de las especificidades del contexto.

- La superación de la visión estrictamente disciplinar enfocada en contenidos, considerando la visión inter y trandisciplinaria mediante proyectos o situaciones problematizadoras que permitan articular al aula, la comunidad, la cultura, lo social, lo económico, lo político y lo emergente en la sociedad.

- Una formación crítica, propositiva y transformadora que promueva el ejercicio para la vida democrática y la construcción de ciudadanos y ciudadanas activos en el ejercicio de sus derechos y deberes.

- Una formación que construya identidades personales que permitan fortalecer la autoestima docente.

- Una formación que construya identidades nacionales, sociales y terrenales.

- Una formación que permita superar la tensión teoría-práctica y la conceptualice en una relación dialéctica, es decir, en la cual una dialoga con la otra y se integren como un todo. 
- Una formación que desde la complejidad, asuma la transitoriedad del conocimiento, su desconstrucción y reconstrucción permanente, pues no existen verdades acabadas.

- Una formación que en clave de competencia asuma como ejes la reflexión y la investigación-acción y que permita superar la concepción transmisiva del conocimiento, el aislamiento del trabajo docente y hacer de esta formación un espacio vivencial de problematización de los procesos de aprendizaje, generación de preguntas y propuestas de solución a las situaciones problemas que caracterizan la práctica.

- Una formación que articule la formación inicial con la formación continua durante todo el trayecto profesional docente.

- Una formación que integre los procesos formativos docentes con las TIC, la interculturalidad, la ética y los valores.

\section{Conclusiones}

La formación docente como factor relevante de un sistema educativo de calidad, debe estar articulada a la realidad del contexto: La escuela, la familia, la comunidad, el país, el mundo. Sin ese diálogo permanente, es imposible que los docentes integren el hábito de promover aprendizajes situados como parte indispensable de su trabajo en aula. Son precisamente esos aprendizajes los que favorecerán el desarrollo de las competencias requeridas para hacer otra relecturas de la realidad y darle pertinencia a sus intervenciones.

Se sabe que aunque los cambios en educación se ven a largo plazo, se necesita un esfuerzo sostenido en las políticas docentes que permitan alcanzar las transformaciones educativas aspiradas.

En estos momentos, la sociedad exige la mejora de la formación docente lo cual plantea decisiones de políticas integrales, voluntad política y esfuerzos de coordinación tanto a lo interno del sistema como a nivel inter institucional a fin de dar respuestas a transformaciones educativas que son impostergables. 


\section{Referencias bibliográficas}

Aguerrondo, I. \& Braslasvky, C. (2003). Escuelas del futuro en sistemas educativos del futuro. Buenos Aires: Editorial Paidós.

Anijovich, R. (2009) .Transitar la formación pedagógica. Buenos Aires: Editorial Paidós.

Assmann, H. (2002). Reencantar la educación. Madrid: Narcea.

Colectivo Argentina de Docentes. (2009). Investigación educativa y trabajo en red. Buenos Aires: Noveduc Libros.

Fullan, M. \& Hargreaves, A. (1997). ¿Hay algo por lo que merezca la pena luchar en la escuela? Sevilla: Ediciones Morón.

López, N. (2007). Escuela y contexto social en América latina. Cuando la globalización llega al aula. Caracas: Federación Internacional de Fe y Alegría.

Marcelo, G. \& Vaillant, D. (2009). Desarrollo profesional docente. Madrid: Narcea.

Ministerio de Educación Superior, Ciencia y Tecnología. (2010). Plan reformulación de la formación docente. Santo Domingo: El autor.

Ministerio de Educación de Educación de República Dominicana. (2004). [Ord. 5'2004, Art. 2]. Santo Domingo: el autor.

Morin, E. (1999). La cabeza bien puesta. Buenos Aires: Ediciones Nueva Visión.

Scheker, A. et al. (2003). Situación de la escuela dominicana. En Reinventar la escuela ¿Qué opciones?: Reflexiones sobre el futuro de la escuela y educación en la Republica Dominicana. Santo Domingo: Centro Poveda y Oficina Nacional UNESCO en Santo Domingo. 
Secretaría de Estado de Educación. (2004). Ordenanza 8'2004. Santo Domingo: Sistema Nacional de Formación Docente.

Tallone, A. et al. (2010). El desafío de la convivencia escolar: Apostar por la escuela. En Educación, valores y ciudadanía. Metas educativas 2021. Madrid: Organización de Estados Iberoamericanos (OEI).

Torres, R. (1996). Nuevas formas de aprender y enseñar. Recuperado de http://www.fronesis.org

Torres, J. (2011). El curriculum oculto. Madrid: Ediciones Morata.

Vaillant, D. (2004). Construcción de la profesión docente en América Latina: Tendencias, temas y debates. Santiago de Chile: PREAL.

Wallestern I, (2006). Abrir las ciencias sociales. México DF: Siglo XXI. 


\section{Celeste Abréu Van Grieken}

Maestra dominicana egresada de la Universidad Autónoma de Santo Domingo (UASD) y del Instituto Tecnológico de Santo Domingo (INTEC). Posee una amplia trayectoria profesional como docente de los niveles primario, secundario y superior en los cuales también ha desempeñado funciones de gestión docente. Ha sido asesora Pedagógica de centros educativos privados, del Centro Cultural Poveda (CCP) y del Ministerio de Educación de la República Dominicana (MINERD). Desde este Ministerio, fue asesora del Instituto Nacional de Formación del Magisterio (INAFOCAM) y actualmente se desempeña como asesora-coordinadora Técnica del Viceministerio de Certificación y Desarrollo de la Carrera Docente del MINERD. Sus publicaciones incluyen artículos y ponencias sobre temas educativos de actualidad.

Correo electrónico: abreuceleste@hotmail.com 
